\title{
Sistemas de manejo, preinstalación, instalación y resolución de audiencias en el Ecuador
}

\section{Management systems, pre-installation, installation and resolution of audiences in Ecuador}

\author{
MSc, Miguel Eduardo Costaín Vásquez ${ }^{1}$ \\ mecostain@ug.edu.ec \\ MSc, Washington Rene Astudillo Orellana ${ }^{2}$ \\ wrastudillo@ug.edu.ec
}

Recibido: 1/09/2018; Aceptado: 1/11/2018

\begin{abstract}
RESUMEN
Los modelos adversariales fueron instaurados en el Ecuador en todas sus materias. Un modelo de justicia basado en audiencias requiere a un Juez preparado no solo para conducir de forma adecuada una audiencia, sino también, una preparación para poder almacenar y sistematizar información de forma perfecta. El presente trabajo de investigación nos aclara la forma como se debe no solo preinstalar una audiencia en un modelo adversarial, sino instalarla, desarrollarla y resolverla de forma adecuada en función del tipo de procedimiento invocado.
\end{abstract}

Palabras Clave: audiencia, adversarial, procesal

\begin{abstract}
The adversarial models were established in Ecuador in all its subjects. A model of justice based on audiences requires a judge prepared not only to conduct an audience adequately, but also, a preparation to be able to store and systematize information perfectly. This research work clarifies the way we should not only preinstall an audience in an adversarial model, but also install it, develop it and solve it properly according to the type of procedure invoked.
\end{abstract}

Keywords: hearing, adversarial, procedural

\footnotetext{
1 Universidad de Guayaquil, Guayaquil, Ecuador.

2 Universidad de Guayaquil, Guayaquil, Ecuador.
} 


\section{Introducción}

En la actualidad, el Ecuador en su sistema procesal, volcó su postura hacia los modelos adversariales y decisiones judiciales adoptadas en audiencia. Nos enfrentamos entonces a un sistema basado en la oralidad. Empero: ¿Cómo se produjo este cambio en el Ecuador?

Los intentos de implementar un sistema oral en materia de administración de justicia en el Ecuador, vienen desde el año de 1998, en el cual, ya se otorgaba el tiempo de cuatro años para que el entonces Congreso Nacional y la Función Judicial, implementen el sistema ${ }^{3}$. Así lo apreciamos en la disposición transitoria séptima de la Constitución de 1998, que indicaba: "La implantación del sistema oral se llevará a efecto en el plazo de cuatro años, para lo cual el Congreso Nacional reformará las leyes necesarias y la Función Judicial adecuará las dependencias e instalaciones para adaptarlas al nuevo sistema(...)"

El primer cambio se produce en materia penal. En julio del año 2001 mediante la vigencia del entonces denominado "Código de Procedimiento Penal", que cambió el sistema inquisitivo e implementó el -hasta ese entonces- novedoso sistema acusatorio oral.

Otras materias trataron de implementar el mismo sistema, como por ejemplo la materia laboral, sin embargo, la falta de equipos técnicos, así como también la falta de manejo de sistemas y técnicas de litigación oral y argumentación jurídica, provocó que este sistema no se implemente en una verdadera forma.

En materia de Garantías Jurisdiccionales, también existió un avance en cuanto a la oralidad, sin embargo, los problemas propios de la constitución de la época, como por ejemplo la falta de coercitividad sobre las "resoluciones" emitidas por los Jueces, así como también el hecho de que el Juez no deba resolver en la misma audiencia, provocaba que estas no cuenten con un sistema de inmediación que permita a la Jueza o Juez estar en contacto permanente con el hecho y las pruebas puestas a su conocimiento, provocando, por ejemplo, que en los denominados amparos constitucionales, las audiencias se celebren incluso sin la presencia del Juez.

En materia civil, el proceso ordinario, verbal sumario o ejecutivo, desconocían la existencia de la oralidad, pues únicamente se tenían las denominadas audiencias de conciliación o el recurso utilizando por muchos profesionales: La audiencia de estrados. Estos procesos eminentemente escritos, ocasionaban falta de celeridad y retrasos en el proceso. La generación de incidentes en un proceso eminentemente escrito, se convirtió en parte de la cultura procesal del Ecuador.

\footnotetext{
3 art. 194.- La sustanciación de los procesos, que incluye la presentación y contradicción de las pruebas, se llevará a cabo mediante el sistema oral, de normativa el obligar al Congreso Nacional a reformar las leyes existentes y a dar cumplimiento a lo dispuesto en su disposición transitoria séptima.
} 


\section{Desarrollo}

Con toda seguridad afirmamos, que el origen de la problemática en materia procesal en el Ecuador, recayó en la Constitución de la apoca, pues no estableció como una garantía acuerdo con los principios: dispositivo, de concentración e inmediación.

En el nuevo modelo de Estado, esto es el Estado Constitucional de Derechos y Justicia, se cambia la estructura dogmática y orgánica de la Constitución, lo cual obviamente provocó el cambio de la normativa subsecuente.

En la actual constitución existe un mandamiento claro. El Art. 168 numeral 6 de la citada norma indica que la sustanciación de los procesos en todas las materias, instancias, etapas y diligencias se llevará a cabo mediante el sistema oral, de acuerdo con los principios de concentración, contradicción y dispositivo ${ }^{4}$.

Esta disposición, obligó a que, en todas las materias inherentes a la administración de justicia en el Ecuador, se implemente el sistema oral. Producto de ello se diseñó y aplicó las denominadas: "Garantías normativas", las mismas que obligan a que la Asamblea Nacional y todo órgano con potestad normativa adecúen formal y materialmente, las leyes y demás normas jurídicas a los derechos previstos en la Constitución $(. .)^{5}$

En virtud de estas garantías normativas, se diseña la ley Orgánica de Garantías Jurisdiccionales y Control Constitucional, así como también el nuevo Código Orgánico General de Procesos, el cual nos lleva a una oralidad completa, elimina la sorpresa procesal y sobre todo obliga al Juez a resolver motivadamente en las audiencias, garantizando de esta forma los principios de inmediación, concentración y celeridad procesal.

Sistemas de preinstalación de audiencias en materia penal.

El Código Orgánico Integral Penal, establece varios tipos de audiencias en función del procedimiento a seguir y sus respectivas etapas. De esta forma tenemos a la instrucción, la etapa de evaluación y preparatoria de juicio y el juicio.

\footnotetext{
4 art. 168 de la Constitución de la República: La administración de justicia, en el cumplimiento de sus deberes y en el ejercicio de sus atribuciones, aplicará los siguientes principios: 1. Los órganos de la Función Judicial gozarán de independencia interna y externa. Toda violación a este principio conllevará responsabilidad administrativa, civil y penal de acuerdo con la ley. 2. La Función Judicial gozará de autonomía administrativa, económica y financiera. 3. En virtud de la unidad jurisdiccional, ninguna autoridad de las demás funciones del Estado podrá desempeñar funciones de administración de justicia ordinaria, sin perjuicio de las potestades jurisdiccionales reconocidas por la Constitución. 4. El acceso a la administración de justicia será gratuito. La ley establecerá el régimen de costas procesales. 5 . En todas sus etapas, los juicios y sus decisiones serán públicos, salvo los casos expresamente señalados en la ley. 6. La sustanciación de los procesos en todas las materias, instancias, etapas y diligencias se llevará a cabo mediante el sistema oral, de acuerdo con los principios de concentración, contradicción y dispositivo.

5 art. 84 de la Constitución de la República.
} 


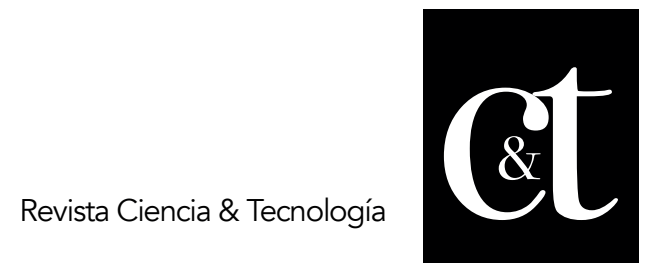

No. 21, 31 de enero de 2019

ISSN impreso: 1390 - 6321

En materia penal, es importante que la secretaria/secretario esté al menos entre quince a veinte minutos antes de la audiencia en la sala respectiva, verifique que testigos existen o que sujetos procesales han comparecido. Una vez que ha constatado para su registro la presencia de las personas convocadas a la audiencia, el secretario, saluda, se identifica y anuncia a los presentes que el Juez está por ingresar.

Una vez que el Juez ingresa a la sala de audiencias, también saludará, se identificará, especificará la unidad judicial a la cual representa y solicitará al secretario, que acorde a la resolución No. 133-2014 del Consejo de la Judicatura, para efectos de la grabación, constate formalmente la presencia de los sujetos procesales y verifique la operatividad de los equipos de grabación y telemáticos.

El secretario, indicará quienes en calidad de sujetos procesales están presentes, especificando a nombre de quien comparecen para luego informar sobre los equipos de grabación. El secretario también indicará que testigos han comparecido por cada sujeto procesal según sea el caso.

Es importante acotar que no existe declaratoria de audiencia fallida por falta de testigos. De no encontrarse presentes todos los testigos para una audiencia de juicio, el Juez puede instalar la audiencia y suspenderla para retomarla en los próximos diez días, tal cual lo establece el Art. 612 del Código Orgánico Integral Penal. En ese momento, con la información positiva de la secretaría, el Juez está listo para instalar la audiencia.

II. Sistemas de preinstalación de audiencias en materia no penal.

En el nuevo procedimiento para materias no penales, resulta trascendental el rol del Juez en el direccionamiento de audiencias. Para ello, antes de entrar a la revisión de las normas pertinentes del Código, debemos hacer las siguientes reflexiones:

Todo Juez debe aplicar un protocolo para direccionamiento de audiencias, el mismo que puede dividirse en tres partes: 1 . Preinstalación de audiencia. 2. Instalación y desarrollo de la audiencia y 3 . Decisión y cierre de la audiencia.

La correcta aplicación de estas tres partes de la diligencia, le permitirá al Juzgador mantener un control adecuado sobre la audiencia y sobre todo tomar buenas y sabias decisiones.

La preinstalación de audiencia, es el momento en el cual la secretaria o secretario de la Unidad Judicial, sala o Tribunal, verifica la presencia de los partes procesales, interesados y testigos que intervendrán en la audiencia. La secretaria o secretario, además de esta actividad, deberá informar al Juez de la causa la operatividad de los equipos de grabación, a fin tener certeza del registro de la audiencia.

Es importante que, en esta preinstalación de audiencia, la Jueza o Juez salude a los presentes, se identifique, e informe a las partes a que unidad pertenece, y luego de ello, dependiendo de la presencia o no de las partes continúe con la instalación de audiencia. El Juez deberá escuchar a las partes procesales sobre los incidentes que se presentaren y deberá resolver cada punto de forma motivada durante la preinstalación de la audiencia. 


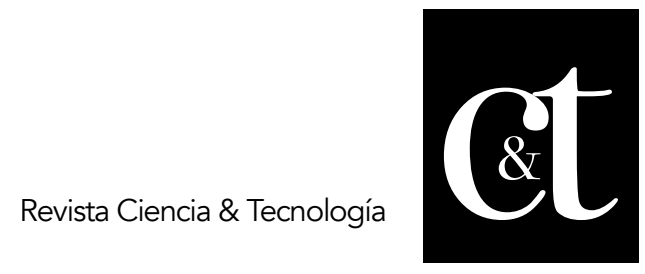

No. 21, 31 de enero de 2019

ISSN impreso: 1390 - 6321

Esta habilidad, permitirá que el Juez controle adecuadamente su audiencia, demostrando solvencia y capacidad para administrar justicia.

Una vez instalada la audiencia, dependiendo del tipo de procedimiento, escuchará a las partes en el orden establecido. Es importante destacar que el Art. 3 del Código Orgánico General de Procesos indica que la o el juzgador, conforme con la ley, ejercerá la dirección del proceso, controlará las actividades de las partes procesales y evitará dilaciones innecesarias. En función de este principio, la o el juzgador podrá interrumpir a las partes para solicitar aclaraciones, encauzar el debate y realizar las demás acciones correctivas. Esto quiere decir, que el rol del Juez en el nuevo modelo procesal oral, es activo. Existen ciertas particularidades que el Juez debe observar al momento de la posible instalación de la audiencia, particularmente lo previsto en el Art. 87 del Código Orgánico General de Procesos, que determina que en caso de inasistencia de las partes se procederá de acuerdo con los siguientes criterios:

1. Cuando quien presentó la demanda o solicitud no comparece a la audiencia correspondiente, su inasistencia se entenderá como abandono.

2. Cuando la o el demandado o la o el requerido no comparece a la audiencia que corresponda, se continuará con la audiencia y se aplicará las sanciones y efectos, entendiéndose siempre que pierde la oportunidad procesal de hacer valer sus derechos. Sin embargo, en caso de retraso, se admitirá su participación, tomando la audiencia en el estado en que se encuentre.

Sistemas de preinstalación de audiencias en Garantías Jurisdiccionales

La instauración de la Justicia Constitucional en el Ecuador, nos brinda nuevas garantías jurisdiccionales, sin embargo, antes de entrar al análisis de fondo de esta problemática, debemos definir conceptos.

El Estado Constitucional de Derechos y Justicia, mantiene una esencia restauradora en materia de derechos y garantías, por ello, la consecuencia inmediata de su puesta en marcha es el nacimiento de nuevas garantías jurisdiccionales.

En el Estado Social y Democrático de Derecho, el Ecuador tenía tres garantías. El denominado amparo constitucional, el habeas corpus y el habeas data, todo esto además de la acción pública por inconstitucionalidad.

Uno de los debates que se generaban durante la vigencia del Estado Social y Democrático de Derechos era el planteamiento sobre la naturaleza de esas garantías jurisdiccionales en el sentido si eran acciones o recursos. En la Constitución actual, dejamos atrás las dudas y se establece claramente que estas garantías jurisdiccionales, serán consideradas acciones.

La Constitución de la República del Ecuador, al momento de diseñar estas nuevas acciones, creó la necesidad de normarlas y adaptarlas a los conceptos de la justicia constitucional, y permitir de este modo un correcto resarcimiento de los derechos fundamentales que podrían ser lesionados, situación que lastimosamente no ocurría en las garantías jurisdiccionales del Estado Social y Democrático, conforme se explicará posteriormente. 


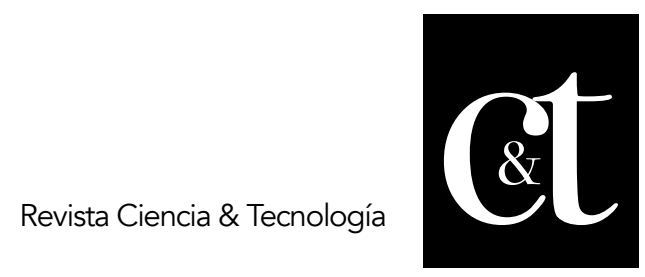

No. 21, 31 de enero de 2019

ISSN impreso: 1390 - 6321

Estas garantías normativas fueron asignadas a la Asamblea Nacional y a todo órgano con potestad normativa, a fin de que se adecuen formal y materialmente los principios constitucionales a leyes.

Producto de este proceso normativo, en la actualidad, las garantías jurisdiccionales se desarrollan con profundidad en la denominada Ley Orgánica de Garantías Jurisdiccionales y Control Constitucional (LOGJCC). ${ }^{6}$

Montaña Pinto (2011), hace bien en afirmar que entre las garantías jurisdiccionales la Constitución reconoce la existencia de siete mecanismos procesales específicos y especializados que permiten a las personas y colectivos, por intermedio de los jueces, garantizar efectivamente sus derechos. Estos son: las medidas cautelares, la acción de protección, el hábeas corpus, la acción de acceso a la información pública, el hábeas data, la acción por incumplimiento y la acción extraordinaria de protección. 7

La acción de protección sustituye al viejo amparo constitucional, con nuevas competencias, amplitud y mecanismos coercitivos, mientras que se diseñan diferencias sustanciales entre la acción de habeas data y acceso a la información pública.

La acción de Habeas Corpus, cambia su ámbito de competencia para la sustanciación con un Juez o Jueces Provinciales - de ser el caso- que analicen específicamente la afectación de la libertad personal, alejándose del concepto anterior del Estado Social y Democrático de Derecho, donde el alcalde, conocía y resolvía este "recurso".

La acción por incumplimiento y la acción extraordinaria de protección, son consecuencia del nuevo modelo de Estado Constitucional de Derechos y Justicia y sus mecanismos para examinar y garantizar la restitución de los Derechos.

Ahora bien, estas garantías jurisdiccionales tienen reglas distintas a la justicia ordinaria; reglas que un Juez debe de observar incluso desde la preinstalación de su audiencia.

Las garantías jurisdiccionales, más allá de la aplicación del principio dispositivo, se rigen por el denominado Iura Novit Curia, es decir que el Juez puede aplicar normas distintas, aunque las partes expresamente no las aleguen. Además, existen diferentes efectos sobre la no comparecencia tanto de legitimado activo como pasivo, así como también la posibilidad de que existan terceros interesados que sin ser considerados como parte procesal, pueden expresarse en la audiencia para que el Juez pueda resolver con más información.

\footnotetext{
6 art. 84.- La Asamblea Nacional y todo órgano con potestad normativa tendrá la obligación de adecuar, formal y materialmente, las leyes y demás normas jurídicas a los derechos previstos en la Constitución y los tratados internacionales, y los que sean necesarios para garantizar la dignidad del ser humano o de las comunidades, pueblos y nacionalidades. En ningún caso, la reforma de la Constitución, las leyes, otras normas jurídicas ni los actos del poder público atentarán contra los derechos que reconoce la Constitución. 7 Juan Montaña Pinto, Apuntes de Derecho Procesal Constitucional, Centro de Estudios Difusión del Derecho Constitucional, Editor Juan Montaña Pinto, Tomo 2, Pág. 105
} 
La Ley Orgánica de Garantías Jurisdiccionales y Control Constitucional, concretamente en su artículo 15 primer numeral ${ }^{8}$, establece que: Se considerará desistimiento tácito cuando la persona afectada no compareciere a la audiencia sin justa causa y su presencia fuere indispensable para demostrar el daño. En caso de desistimiento el expediente será archivado, sin embargo, si el accionado no asiste a la audiencia y estamos frente a la inversión de la carga de la prueba, la audiencia podrá continuar sin su presencia.

Algo importante de acotar, es que el Juez para poder aplicar el numeral 1 del Art. 15 de la Ley Orgánica de Garantías Jurisdiccionales y Control Constitucional, debe observar lo dispuesto por la Corte Constitucional en la sentencia No. 063-14-SEPCC dentro del caso No. 0522-12-EP, que indica: 1. De verificarse únicamente la inasistencia a la audiencia sin justa causa, pero no la indispensabilidad sobre su presencia, la jueza o juez continuará con el desarrollo de la audiencia y dictará sentencia, conforme a lo establecido en la normativa constitucional y legal pertinente. 2. En caso de hallarse frente a una inasistencia sobre la que se haya presentado una justa causa, y de considerar que la presencia de la persona afectada es indispensable, la jueza o juez, después de calificarla como tal, deberá fijar una vez más una nueva fecha y hora para su celebración.

A propósito de la preinstalación de la audiencia en garantías jurisdiccionales, deberá observarse lo siguiente: 1 . Secretaría deberá estar en sala de audiencias, al menos de quince a veinte minutos antes de la audiencia, constatará quienes se encuentran y advertirá que luego hará su ingreso el Juez. 2. El Juez ingresará, saludará, se identificará e indicará a que unidad judicial pertenece y solicitará a la secretaría que le indique quienes se encuentran presentes para la celebración de la audiencia. 3. En función de quienes se encuentren presentes, el Juez deberá observar lo previsto por la regla jurisprudencial de la Corte Constitucional obrante en la sentencia No. No. 063-14-SEP-CC. 4. De existir terceros interesados, acorde a lo previsto en el Art. 12 de la norma antes citada, se los escuchará para que justifiquen su comparecencia y acto seguido se escuchará también al accionante y accionado para que el Juez pueda decidir su participación. 5. Hecho esto, el Juez estará listo para la instalación de la audiencia.

Normas básicas para la instalación de las audiencias.

Podríamos indicar que las medidas adoptadas ya en la instalación de las audiencias son estandarizadas, quizás en materia penal existen más particularidades según el tipo de audiencia.

\footnotetext{
8 art. 15 de la LOGJCC: Art. 15.- Terminación del procedimiento. - El proceso podrá terminar mediante auto definitivo, que declare el desistimiento o apruebe el allanamiento, o mediante sentencia. 1. Desistimiento. - La persona afectada podrá desistir de la acción en cualquier momento por razones de carácter personal que serán valoradas por la jueza o juez. Se considerará desistimiento tácito cuando la persona afectada no compareciere a la audiencia sin justa causa y su presencia fuere indispensable para demostrar el daño. En caso de desistimiento el expediente será archivado.
} 
Por ejemplo, siempre es adecuado que el Juez una vez constatada la presencia de los sujetos o las partes procesales, identifique si se están ventilando derechos o garantías de niñas, niños y adolescentes, pues de ser este el caso, el Juez debe indicar que, al referirse a estos, únicamente lo harán expresando las siglas respectivas.

Una vez instalada la audiencia, el Juez deberá explicar a los sujetos/partes/legitimados, el tipo de audiencia que va a desarrollar, así como también las partes de la misma y de ser el caso las medidas de restricción respectivas.

En materia constitucional, por ejemplo, el Juez deberá indicar que tanto accionante como accionado tendrán veinte minutos para intervenciones iniciales, diez minutos para replica y que la audiencia no terminará sino con la intervención del accionante.

En materia penal, el Juez deberá dirigirse a la persona procesada y explicar la naturaleza de la audiencia respectiva, indicar que derechos le asisten y solicitar si está consciente de la misma. Del mismo modo se deberá dirigir hacia la víctima - en caso de que esté presente- y explicarle sus derechos. Finalizada esta explicación solicitar a los testigos ponerse de pie e indicar que deben estar incomunicados en la sala respectiva para luego dirigirse al público en general e indicar que no se puede interrumpir el desarrollo de la audiencia, debiendo guardar silencio en todo momento.

En materia no penal, es adecuado explicar puntualmente la forma en la cual se desarrollará la audiencia, a fin de que las partes procesales y sus abogados estén claros sobre la naturaleza de la misma y sobre todo puedan conocer los efectos de la falta de apelación en determinados momentos de las audiencias.

Debemos recordar también que el Art. 80 del Código Orgánico General de Procesos ${ }^{9}$, indica que la Jueza o Juez, dentro de sus facultades de dirección podrá indicar a las partes los asuntos a debatir, moderar la discusión, impedir que sus alegaciones se desvíen hacia aspectos no pertinentes y ordenar la práctica de pruebas cuando sea procedente. Asimismo, podrá limitar el tiempo del uso de la palabra de las personas que intervengan, interrumpiendo a quien haga uso manifiestamente abusivo o ilegal de su tiempo. Ejercerá las facultades disciplinarias destinadas a mantener el orden y garantizar su eficaz realización. La o el juzgador dirigirá la audiencia de tal manera que las partes y el público comprendan lo que ocurre.

9 art. 80 del Código Orgánico General de Procesos. 


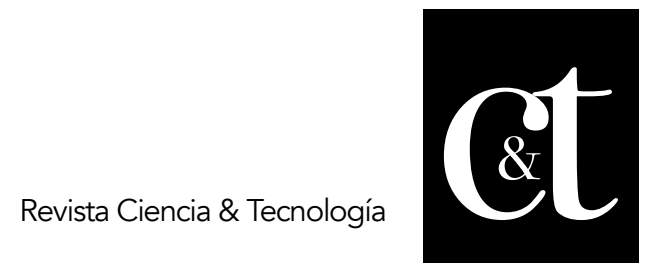

No. 21, 31 de enero de 2019

ISSN impreso: 1390 - 6321

Finalmente podemos indicar, que la correcta aplicación de estas técnicas nos permite sustanciar las audiencias de una forma correcta y sobre todo limitar al máximo los incidentes procesales.

Sistematización de información en audiencias en el Ecuador

El desarrollo de una audiencia y el ejercicio de oralidad deben de ser correctamente direccionados por el Juez. Sin embargo, se debe de tener claro que la finalidad de la audiencia es que el Juez pueda aplicar un principio básico del derecho procesal para resolver, este es la inmediación.

Es necesario que el Juez mantenga un contacto directo con la prueba, pero, además, con las partes o sujetos procesales, para que estos puedan expresarse ante el Juez y presentar cada uno de los elementos o pruebas necesarios para generar convencimiento en el Juzgador.

Esta información brindada por las partes o sujetos procesales no puede perderse. Si bien es cierto toda audiencia en nuestro sistema procesal será grabada conforme lo hemos estudiando en las unidades anteriores, no es menos cierto que el Juez debe tener la habilidad de sistematizar esta información para poder resolver de forma adecuada en cada audiencia.

Para ejecutar esta sistematización de forma adecuada, lo primero que el Juez debe tener claro es que no puede tener elementos de distracción dentro de la sala de audiencias. Si existen teléfonos celulares, es recomendable que estos estén en silencio para no distraer la atención del Juez. Los tiempos que se dan en la audiencia son rápidos y es importante que el Juez observe los detalles de la misma.

Para poder ejecutar este ejercicio de sistematización o almacenamiento de información existen dos técnicas. La primera, almacenar la información de forma electrónica en el computador de la sala de audiencias y la segunda, hacerlo de forma escrita en la libreta de apuntes.

Cada audiencia tiene particularidades y un sistema de información distinta. Para ello, el Juez debe tener muy claro su sistema de direccionamiento de audiencias. Es vital que el Juez al momento de acudir a su audiencia, tenga ya listo en su computador o su libreta datos precisos como el tipo de causa, partes procesales, numero de causa, tipo de audiencia y su fecha; esto ayudará a que la información tenga una correcta organización desde las primas intervenciones.

Podemos resumir la sistematización de información, en tres puntos específicos, estos son: intervenciones iniciales, práctica probatoria o presentación de anuncios probatorios, de ser el caso; y las pretensiones finales en audiencia.

Para el ejercicio práctico y para efectos del presente ensayo, analizaremos la sistematización de la información en alegatos iniciales, practica probatoria y alegatos finales.

El alegato inicial o de apertura.

El alegato inicial o de apertura, según se determine tanto en materia no penal como 
penal, tiene una estructura que tiene que ser observada por el Juez. Una correcta estructuración de este alegato inicial o de apertura permite optimizar tiempos procesales. Su estructura debe ser la siguiente: 1. Pretensión jurídica 2. Descripción de un hecho factico y 3 . Oferta probatoria.

La pretensión jurídica representa la razón de ser de la audiencia. Por ejemplo, si se trata de materia penal y estamos frente una audiencia de juicio, la pretensión jurídica de la fiscalía sería, por ejemplo: Traer a juicio un delito de asesinato, el hecho factico sería el detalle cronológico fechas, tiempos, lugares y personas en las cuales se cometió ese hecho, mientras que la oferta probatoria sería la descripción de las pruebas ser presentadas. A manera de referencia se puede indicar que el denominado alegato de apertura o inicial no es lo mismo que una teoría del caso. El alegato inicial es una promesa que la parte o sujeto procesal ofrece cumplir y probar en audiencia. Por ello, contiene una parte esencial que carece la teoría del caso, esto es la oferta probatoria. Como bien lo señala Reyna Alfaro: Mauet y Baytelman consideran que la teoría del caso parte de una historia, punto de vista, perspectiva, etc. ${ }^{10}$, sin embargo, el alegato inicial es conciso tanto con la pretensión jurídica y el hecho factico, sumada a la existencia de una oferta probatoria que va marcada de congruencia, es decir, que debe existir una lógica armonizada entre lo prometido y lo ofertado.

Ya en el transcurso de la audiencia, para la aplicación de un buen sistema de almacenamiento de información el Juez puede trabajar con una ficha de sistematización que recoja los tres elementos de este alegato inicial, conforme lo detallamos en el siguiente gráfico:

\begin{tabular}{|l|}
\hline Pretensión jurídica: \\
\hline Hecho Factico: \\
\hline Oferta Probatoria: \\
\hline
\end{tabular}

\section{Gráfico 1. Sistema de Almacenamiento de información}

Fuente: Elaboración propia

La prueba testimonial y sistemas de examen y contra examen

Otro de los puntos más importantes en el desarrollo de una audiencia, vienen a ser los denominados sistemas de interrogatorios directos y cruzados, así como también los sistemas de objeción. 


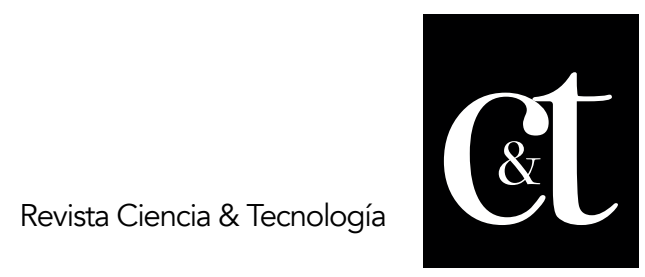

No. 21, 31 de enero de 2019

ISSN impreso: 1390 - 6321

El Juez en la audiencia, debe estar atento a la práctica probatoria, especialmente a la testimonial. Podríamos resumir que la prueba actúa en función del tipo de procedimiento, empero, podríamos resumir que existen tres clases básicas de prueba: La testimonial, pericial y documental.

En el Ecuador, al existir modelos adversariales y de justicia en audiencias, el tipo de prueba que mayor análisis amerita es la prueba testimonial.

Para empezar, debemos indicar que el Juez debe ser amigable con su testigo, pero claro en las advertencias al momento en que ingrese a la sala de audiencias. Se debe recordar también que la prueba testimonial varía en función del tipo de procedimiento. En garantías jurisdiccionales conforme lo establece la Ley Orgánica de Garantías Jurisdiccionales y Control Constitucional, en la audiencia pública el Juez puede escuchar las "versiones" de terceros ${ }^{11}$, es decir, que en este procedimiento, el Juez no tomará ningún juramento al versionante, pues al ser una acción rápida, sencilla e informal, la Ley no exige las formalidades propias de la justicia ordinaria; lo cual obviamente si ocurre en las audiencias de juicio, en materia penal y materia no penal, pues la ley de la materia denomina a estas intervenciones como testimonios y el juramento es un requisito indispensable, exceptuando en materia penal el testimonio de la persona procesada.

La forma de receptar el juramento debe ser sencilla y clara. El Juez al momento en que el testigo pasa a la sala de audiencias, debe recordar que este fue llamado en tal calidad por una de las partes y como consecuencia deberá responder a cada una de las preguntas solicitadas. Su mirada debe estar siempre en dirección al Juez y si escucha la palabra objeción deberá suspender su narrativa y esperar a que este último la resuelva. Con esta explicación se procederá con el juramento, el cual bajo ningún concepto puede enfocarse en la religión u honor, pues dicha disposición existente en el antiguo código de procedimiento civil ya no existe.

El Juez para proceder con el juramento solicitará al auditorio ponerse de pie, el testigo levantará su mano derecha y se le consultará si jura decir la verdad de todo lo que supiere o fuere preguntado en la audiencia. Hecho esto, advertirá que, en caso de mentir, comete el delito de perjurio. Luego, el testigo tomará asiento en su lugar al igual que el público en general y el Juez concederá la palabra al titular de la prueba para iniciar el examen o interrogatorio directo.

Vale acotar, que la terminología en la litigación oral varía en función del tipo de procedimiento. Es importante que el Juez sepa distinguirlos y aplicarlos al caso concreto. En materia penal, al referirnos al sistema de preguntas y repreguntas, se debe indicar que se trata del examen y contra examen, mientras que, en materia no penal, tenemos el interrogatorio y el contrainterrogatorio. Los jueces multi competentes deben emplear un léxico adecuado en sus audiencias.

11 ley Orgánica de Garantías Jurisdiccionales y Control Constitucional, Art. 14 


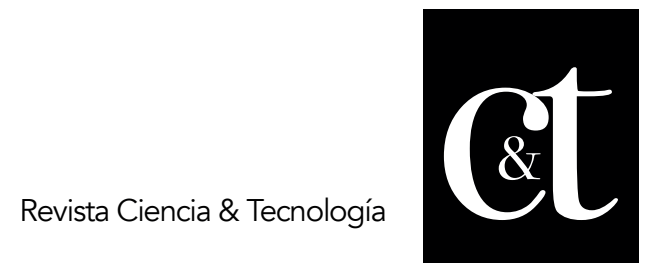

No. 21, 31 de enero de 2019

ISSN impreso: 1390 - 6321

El examen o interrogatorio, siempre debe procurar elaborar preguntas directas y cerradas a fin de obtener calidad de información; se recomienda hacerlo en dos tiempos: El primero, a través de un sistema de acreditación al testigo que asegure que este no es improvisado y no tiene motivo para mentir, mientras que en un segundo momento ya se puede preguntar sobre el centro de la controversia. Ambos tiempos se deben manejar dentro de la misma intervención inicial del abogado.

Un ejemplo de sistema de acreditación al testigo por ejemplo sería: ¿Qué tiempo de experiencia tiene como perito? ¿Se encuentra acreditado como tal en el Consejo de la Judicatura? El sistema de acreditación del testigo o perito, puede ser el mismo tanto en materia no penal como en materia penal.

Otra diferencia existente en el tema de la litigación oral en audiencias entre los procedimientos penales y no penales, vienen a ser los tipos de preguntas que se pueden hacer dentro del interrogatorio directo. Existen diferencias sustanciales en los sistemas de contrainterrogatorio no penal y el contra examen en materia penal, sin embargo, iniciaremos explicando en primer término las similitudes en el interrogatorio o examen directo.

Las preguntas deben ser directas y cerradas. Se debe evitar siempre la formulación de las preguntas compuestas. Un correcto sistema sería llevar un correcto orden de ideas en el examen o interrogatorio. Por ejemplo: ¿Usted que diligencias realizó en la presente audiencia? ¿Cuáles fueron las técnicas aplicadas en su pericia? ¿Cuáles son sus conclusiones?

La formulación de preguntas compuestas o abiertas, provoca que el testigo emita información que no será de calidad, pues será este quien controle la información que desea brindar y la información que a su vez desea ocultar.

El Art. 502 del Código Orgánico Integral Penal en las reglas generales de las audiencias, indica que los sujetos procesales podrán realizar preguntas u objetarlas, y la o el juzgador deberá resolver la objeción para que la persona la conteste o se abstenga de hacerlo. No se podrán formular preguntas auto incriminatorias, engañosas, capciosas o impertinentes. No se podrán formular preguntas sugestivas en el interrogatorio, excepto cuando se trate de una pregunta introductoria o que recapitule información ya entregada por el mismo declarante. Podrán hacerse preguntas sugestivas durante el contra examen. ${ }^{12}$

Bajo esta premisa, se puede indicar que la pregunta sugestiva, en materia penal, puede realizarse desde el examen directo como mecanismo de introducción de información y de igual forma en el contra examen, lo cual marca a su vez una diferencia con la materia no penal, pues la pregunta sugestiva en esta materia tiene escenarios diversos para ser aplicada. El Código Orgánico General de Procesos, determina que la pregunta sugestiva se podrá realizar en el contrainterrogatorio únicamente cuando se trate de una declaración de parte o en su defecto cuando el testigo haya sido declarado como hostil, así lo define el Art. 177 numeral 7 de la referida norma al indicar: "Podrán formularse preguntas sugestivas sobre temas introductorios que no afecten a los hechos controvertidos, recapitulen información ya aportada por la o el declarante o la o el juzgador haya calificado al testigo como hostil. También están permitidas en el contrainterrogatorio cuando se practique la declaración de una parte a pedido de la otra. ${ }^{13}$ 


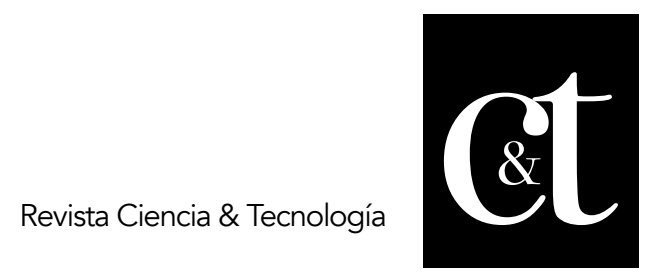

No. 21, 31 de enero de 2019

ISSN impreso: 1390 - 6321

En materia no penal, también existen preguntas que no serán permitidas. Por ejemplo las inconstitucionales, impertinentes, capciosas, obscuras, compuestas y aquellas destinadas a coaccionar ilegítimamente al declarante, así como también las que acarreen responsabilidad penal a la o el declarante, sugestivas, vagas, confusas, impertinentes o hipotéticas por opiniones o conclusiones, exceptuando las preguntas hipotéticas en el caso de los peritos dentro de su área de experticia, sin embargo existen ciertos tipos de preguntas que el Juez puede objetar de forma directa por tutela judicial efectiva y otras en las cuales el Juez debe esperar el sistema de objeción de las partes aplicando el principio dispositivo.

El Código Orgánico General de Procesos, define en su Art. 176 que las partes podrán objetar de manera motivada cualquier pregunta, en particular las que acarreen responsabilidad penal a la o el declarante, sean capciosas, sugestivas, compuestas, vagas, confusas, impertinentes o hipotéticas por opiniones o conclusiones(... $)^{14}$ mientras que el Art. 177 numeral 8 del mismo Código indica que el Juez negará las preguntas inconstitucionales, impertinentes, capciosas, obscuras, compuestas y aquellas destinadas a coaccionar ilegítimamente al declarante. ${ }^{15}$

De lo anterior se puede concluir que el Juez podrá objetar de forma directa aquellas preguntas inconstitucionales, impertinentes, capciosas, obscuras, compuestas y aquellas destinadas a coaccionar ilegítimamente al declarante, tomando en consideración la tutela judicial efectiva aplicable a todo tipo de procesos, sin embargo, la pregunta sugestiva, conforme lo establece el Art. 176 de la norma previamente citada, requiere un sistema de objeción de parte por cuanto la misma tiene diversos escenarios.

Los sistemas de objeciones, deben ser correctamente atendidos por el Juez. Si alguna de las partes desea objetar una pregunta deberá hacer conocer del particular al Juez al momento de la audiencia, pronunciando la palabra "objeción". Una vez que el testigo silencia su intervención producto de la objeción, el Juez deberá solicitará al peticionario el fundamento de su objeción. Con dicha información el Juez calificará la misma e indicará si se declara con o sin lugar, siempre explicando la pertinencia de su decisión, conforme en ensayos posteriores lo detallaremos.

\footnotetext{
12 Código Orgánico Integral Penal. Art. 502.

13 Art. 177 No. 7 del Código Orgánico General de Procesos.

14 Art. 176 del Código Orgánico General de Procesos.

15 Art. 177 No. 8 del Código Orgánico General de Procesos.
} 
Para sistematizar o almacenar toda esta información dada en audiencias, es importante que el Juez lleve un control adecuado en su sistema de apuntes, donde se determine: nombres completos del testigo, su identificación, tipo de testimonio (terceros, parte, perito, etc.), la diligencia que practicó (peritos), tipo de diligencia (peritos) y la razón de su testimonio. De la misma forma el Juez deberá identificar y ubicar correctamente en su sistema de apuntes la parte procesal o sujeto procesal que ha solicitado la diligencia. En caso de que por medio del contra examen o el contrainterrogatorio se desacredite al testigo $o$ en su defecto se resalten contradicciones en su testimonio, el Juez deberá reflejar de forma puntual esa contradicción en su sistema de apuntes, por cuanto al momento de anunciar su decisión, le permitirá justificar la valoración de este testimonio dentro de su sentencia.

\section{El alegato final}

El alegato final tiene una carga persuasiva. Representa una revisión entre la oferta probatoria y la práctica de la prueba, de tal suerte que en las intervenciones finales el Juez pueda comparar de forma clara que fue lo que se pretendió probar con relación a lo realmente probado.

En este alegato final, las partes o sujetos procesales tratan de resumir toda la prueba practicada en la audiencia. Si bien es cierto, este alegato tiene una carga persuasiva, el Juez debe mantener su objetividad.

En palabras de Reyna Alfaro (2015), la persuasión viene a ser un mecanismo en el cual las partes procesales buscan convencer a un tercero, el Juez, de la mayor validez de sus argumentos. Allí radica justamente la importancia de la labor del abogado litigante: Que el receptor reciba el mensaje requiere que el mensaje y el mensajero sean adecuados. ${ }^{16}$

Ahora bien: ¿Cuál es el mensaje correcto que debe recibir un Juez? ¿Cuál es la información que debe de tener en este alegato?

Para responder al cuestionamiento, debemos indicar que el mensaje correcto es aquel que tiene congruencia entre lo que se promete y lo que se prueba. Si prometí probar mi tesis con tres testigos, dos peritos y dos pruebas documentales, estas debieron ser producidas en la etapa probatoria y todas deben coincidir en la tesis inicial.

Si la práctica probatoria no fue eficiente y no guarda relación con mi planteamiento inicial, entonces la estrategia habría fracasado.

El Juez debe trabajar con sistema de "Check list" para ir determinando por un lado lo ofertado como prueba y en otro casillero la determinación de cumplimiento o no de lo prometido.

16 Luis Miguel Reina Alfaro, Obra citada, pág. 55 


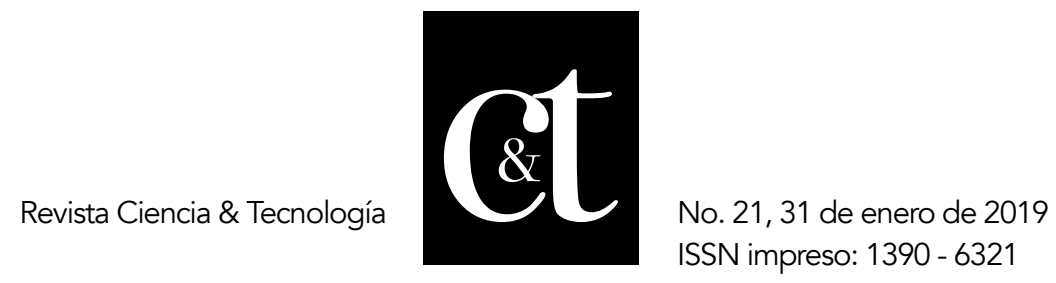

Dependiendo del tipo de procedimiento, las partes o sujetos procesales deberán cumplir con ciertos parámetros, por ejemplo, en materia penal, un fiscal al momento de concluir su alegato deberá ser muy claro en determinar el delito por el cual solicita sentencia, el grado de participación de la persona procesada, el tiempo de condena que desea se imponga, la multa respectiva y el mecanismo de reparación integral a la víctima. En materia no penal, las partes procesales deben concluir sus intervenciones justificando que su prueba determina su pretensión con relación al objeto de la controversia, mientras que en garantías jurisdiccionales se deberá justificar los argumentos expuestos en la audiencia pública, tomando en consideración los casos de inversión de la carga de la prueba.

Finalmente, se concluye que el correcto proceso de almacenamiento de información provoca que el Juez pueda tomar decisiones correctas en la misma audiencia.

\section{Referencias bibliográficas}

Código Orgánico de la Función Judicial. Quito, Ecuador. 9 de marzo de 2009

Código Orgánico General de Procesos. Quito, Ecuador. 22 de mayo de 2015

Código Orgánico Integral Penal. Quito, Ecuador. 10 de febrero de 2014

Constitución de la República del Ecuador. Quito, Ecuador. 20 de octubre de 2008

Ley Orgánica de Garantías Jurisdiccionales y Control Constitucional. Quito, Ecuador.

Montaña Pinto, Juan (2011). Apuntes de derecho procesal constitucional: parte especial: garantías constitucionales en Ecuador. Quito Corte Constitucional para el Período de Transición.

Reyna Alfaro, Luis Miguel (2015). Persuasión y Storytelling aplicados a la defensa penal. Pamplona. España. 